Revista Ceuma Perspectivas, Edição Especial. I Fórum de Meio Ambiente do Estado do Maranhão, Ceuma.

Vol. 30, nº1, 2017.

ISSN Eletrônico: 2525-5576.

\title{
ANÁLISE DOS PARÂMETROS FÍSICO-QUÍMICOS E MICROBIOLÓGICOS DA ÁGUA DO RIO PACIÊNCIA, SÃO LUÍS, MA
}

\section{ANALYSIS OF THE PHYSICO-CHEMICAL AND MICROBIOLOGICAL PARAMETERS OF THE WATER OF THE PATIENCE RIVER, SÃO LUÍS, MA}

Weslley Phelix Silveira Rabelo ${ }^{1}$, Giselle Santos Araújo ${ }^{2}$, Jethania Glasses Cutrim Furtado ${ }^{3}$, Silvio Carvalho Marinho ${ }^{4}$, Herika Polyana Silva Martins Rabelo ${ }^{5}$, Alyson da Luz Pereira Rodrigues ${ }^{6}$, Wolia Costa Gomes ${ }^{7}$

RESUMO: Este artigo visa identificar os parâmetros físico-químicos e microbiológicos da água do Rio Paciência, São Luís, Maranhão, tais como: identificar os pontos de relevância para o estudo no Rio Paciência, realizar a amostragem dos parâmetros físicoquímicos e microbiológicos, verificar possíveis níveis de contaminação comparando com a Resolução CONAMA 357 de 17/03/2005 e indicar possíveis medidas mitigadoras para a área de estudo. Foram realizadas visitas in loco para a determinação dos pontos de coleta para a amostragem e posterior análise microbiológica e físicoquímica da água, seguido de registros fotográficos e da localização geográfica (GPS) da área. Dos parâmetros físico-químicos analisados, o pH, a salinidade e os sólidos totais dissolvidos estão enquadrados na Resolução CONAMA 357/05, para água doce de classe 2. As análises microbiológicas realizadas com a técnica do Substrato Cromogênico Definido (Colilert), constataram nas amostras a presença de Coliformes Totais e E. Coli. Portanto, recomenda-se para redução da poluição causada no Rio Paciência, uma ação do Poder Público para minimizar os impactos causados pela descarga de efluentes neste corpo hídrico. Propõe-se também medidas de educação ambiental para as pessoas que moram no entorno da área.

PALAVRAS-CHAVE: Qualidade da Água. Níveis de contaminação. Parâmetros Físico-químicos.

\footnotetext{
${ }^{1}$ Administrador, Mestrando Meio Ambiente na Universidade Ceuma. Grupo de Estudo Química Tecnológica e Ambiental. E-mail: weslleyphelix@ hotmail.com

2 Tecnóloga em Gestão Ambiental. CEST. E-mail: giselle.santosaraujo@gmail.com

3 Química, Docente. CEST. E-mail: j.glassesferreira@outlook.com

4 Química, Docente da Faculdade Estácio São Luis. E-mail:silviomarinho@yahoo.com.br

5 Nutricionista, Mestranda Biologia Parasitaria na Universidade Ceuma. E-mail:

herikapolyana@hotmail.com

${ }^{6}$ Eng. Produção, Mestrando Meio Ambiente. Ceuma. Bolsista. Grupo de Estudo Quimica Tecnológica e

Ambiental. E-mail:alisonluz93@outlook.com

7 Química, Docente na Universidade Ceuma. E-mail: woliacg@gmail.com
} 
Revista Ceuma Perspectivas, Edição Especial. I Fórum de Meio Ambiente do Estado do Maranhão, Ceuma.

Vol. 30, $\mathrm{n}^{\circ} 01,2017$. ISSN Eletrônico: 2525-5576.

ABSTRACT: This paper aims to identify the physico-chemical and microbiological parameters of the water of the Paciência River, São Luís, Maranhão, such as: to identify the relevant points for the study in the Patient River, to carry out the sampling of the physical-chemical and microbiological parameters, to verify possible levels of contamination compared to CONAMA Resolution 357 of 03/17/2005 and indicate possible mitigating measures for the study area. On-site visits were carried out to determine the collection points for sampling and subsequent microbiological and physical-chemical analysis of the water, followed by photographic records and the geographical location (GPS) of the area. The physico-chemical parameters analyzed, the $\mathrm{pH}$, salinity and total dissolved solids are included in CONAMA Resolution 357/05, for freshwater of class 2. Microbiological analyzes performed with the technique of the Definite Chromogenic Substrate (Colilert) the presence of Total Coliforms and E. coli. Therefore, it is recommended to reduce the pollution caused in the Paciencia River, an action of the Public Power to minimize the impacts caused by the discharge of effluents in this water body. Environmental education measures are also proposed for people living in the area.

KEYWORDS: Water quality. Levels of contamination. Physicochemical Parameters.

\section{INTRODUÇÃO}

No decorrer do tempo, o processo de urbanização tem se expandido constantemente, e assim projetando uma grande transformação no meio ambiente (PONSADAILAKSHMI et al., 2018). Nesse contexto, a água é de extrema importância para o ser humano, e a sua disponibilidade deve ser satisfatória, tanto em quantidade quanto em qualidade, para atender as necessidades dos indivíduos (WU et al., 2018). Assim, os parâmetros físico-químicos e microbiológicos devem estar de acordo com os padrões de qualidade da água (RAMDANI et al., 2012).

A água possui impurezas, que podem ser encontradas, em grandes ou pequenas quantidades, dependendo da sua origem e do uso a que foi designado (RODRIGUES et al., 2009). Essas impurezas presentes na água podem obter valores que ocasionam prejuízos ao homem e ao ambiente, sendo o principal causador de doenças patogênicas e o impacto ao meio ambiente (RIOS, 2009). 
Revista Ceuma Perspectivas, Edição Especial. I Fórum de Meio Ambiente do Estado do Maranhão, Ceuma.

Vol. 30, nº1, 2017. ISSN Eletrônico: 2525-5576.

Os problemas que afetam diretamente a qualidade da água de rios ocorrem de diversas formas, como o lançamento de esgotos domésticos tratados ou não tratados de forma adequada; a falta ou incapacidade do modo que os efluentes industriais são verificados, de forma que sua destinação seja feita corretamente algo que a fiscalização dessas indústrias não faz com eficiência; do desmatamento; e as práticas agrícolas incorretas (MACEDO, 2003).

A maior parte das doenças transmitidas para o homem é ocasionada por microrganismos que são provenientes do ar, água, alimento e contato. De acordo com a forma de utilização da água devemos considerar as propriedades de qualidade definidas pelos parâmetros e padrões de potabilidade descritos por lei e normatizações sanitárias (OCHOO; VALCOUR; SARKAR, 2017). A averiguação desses parâmetros e padrões reforça a garantia do uso ou consumo da água para que não apresente riscos à saúde humana (LYONS et al., 2015).

Diante dessa problemática, a qualidade da água do Rio Paciência está sendo afetada por ações antrópicas, decorrente da urbanização, do lançamento de efluentes domésticos em seu curso de água, gerando assim uma grande degradação neste Rio. Assim, a realização desta pesquisa está relacionada ao estado que este corpo hídrico se encontra.

Nesse contexto, este artigo tem por objetivo geral: identificar os parâmetros físico-químicos e microbiológicos da água do Rio Paciência, São Luís, Maranhão; e como específicos: identificar os pontos de relevância para o estudo no Rio Paciência, realizar a amostragem dos parâmetros físico-químicos e microbiológicos nos pontos de relevância, verificar possíveis níveis de contaminação, comparando com a Resolução CONAMA 357 de 17/03/2005 e indicar possíveis medidas mitigadoras para a área de estudo.

\section{MATERIAL E MÉTODOS}

Esta pesquisa foi realizada em duas etapas. A primeira etapa constituiu em um levantamento bibliográfico em diversos bancos de dados, relatórios de órgãos públicos e privados, bibliotecas de instituições de ensino e em meio eletrônico, para a construção 
Revista Ceuma Perspectivas, Edição Especial. I Fórum de Meio Ambiente do Estado do Maranhão, Ceuma.

Vol. 30, n⿳01, 2017. ISSN Eletrônico: 2525-5576.

de argumentos consistentes e coesos sobre a temática abordada. Na segunda etapa, visitas in loco no dia 03 de outubro de 2015, para a determinação dos pontos de coleta para a realização da amostragem da água, seguido de registros fotográficos.

\subsection{Procedimentos Metodológicos}

A realização das visitas in loco ocorreu no mês de outubro de 2015, onde houve a identificação dos pontos de coleta da água, determinados como P 01 e P 02, cujas coordenadas são: P01 05 79' 21,0” S 97 19'92,9” W e o P $0205^{\circ} 87^{\prime}$ 47,8” S $97^{\circ} 15^{\prime} 47,7$ ' W. Em seguida, com a determinação dos pontos, foi realizada no local a análise físico-química da água e a coleta das amostras para a análise microbiológica.

\subsection{Enquadramento dos Corpos Hídricos}

De acordo com a Resolução CONAMA (Conselho Nacional do Meio Ambiente) 357 de março de 2015 no art. $2^{\circ}$ um corpo hídrico é classificado sendo de água doce quando sua salinidade for igual ou inferior a $0,5 \%$, sendo assim as amostras coletadas se enquadram nesse limite classificando esse corpo hídrico como de água doce.

No artigo $4^{\circ}$ da mesma Resolução de acordo com a categoria este corpo hídrico está classificado em classe 2, águas que podem ser destinadas: a) ao abastecimento para consumo humano, após tratamento convencional; b) à proteção das comunidades aquáticas; c) à recreação de contato primário, tais como natação, esqui aquático e mergulho, conforme a Resolução CO NAMA n 274, de 2000; atualmente esse corpo hídrico não está sendo utilizado para essas atividades, d) à irrigação de hortaliças, e) à aquicultura e à atividade de pesca.

\subsection{Análise Físico-química}

Utilizando o Kit Multiparâmetro, efetivou-se a análise dos seguintes parâmetros: $\mathrm{pH}$, temperatura, salinidade, sólidos totais dissolvidos, oxigênio dissolvido, condutividade elétrica.

A coleta das amostras para a análise bacteriológica visando identificar coliformes termo tolerantes e totais foram coletadas em garrafas de $300 \mathrm{ml}$, lacradas de forma correta, acondicionadas em isopor e armazenadas na geladeira para preservar a 
Revista Ceuma Perspectivas, Edição Especial. I Fórum de Meio Ambiente do Estado do Maranhão, Ceuma.

Vol. 30, nº1, 2017. ISSN Eletrônico: 2525-5576.

condição das amostras até a realização de sua análise. Posteriormente, as amostras acondicionadas em isopor foram transportadas ao laboratório de Microbiologia da Faculdade Santa Terezinha (CEST), para a realização das análises bacteriológicas.

\subsection{Procedimentos de Análise Bacteriológica}

Para a realização da análise utilizou-se a técnica do substrato cromogênico definido (Colilert), a detecção desses microrganismos por esse método torna mais fácil a identificação da presença de coliformes totais e E.Coli na amostra a ser analisada.

Para a análise, as amostras acondicionadas no isopor, utilizando frascos de $500 \mathrm{ml}$ marcados os frascos do ponto 01 e do ponto 02, onde realizou-se duas análises de cada ponto, para cada $100 \mathrm{ml}$ da amostra utilizou-se um floconete do Colilert, em seguida as amostras eram homogeneizadas e colocadas na estufa em uma temperatura de $37^{\circ}$ por um tempo de 24 horas.

\section{RESULTADOS E DISCUSSÃO}

\subsection{Parâmetros Físico-químico}

\subsubsection{Temperatura}

Para Queiroz (2003), um dos parâmetros mais importantes para os estudos dos ambientes aquáticos é a temperatura, pois esse parâmetro influencia diretamente a cinética dos processos metabólicos, como a respiração; a solubilidade dos gases dissolvidos, como o oxigênio.

Nesse parâmetro a temperatura da nascente do Rio Paciência varia entre $27,1 C^{\circ}$ a 27,39C , sendo que na Resolução CONAMA 357 de março de 2005 não consta o valor máximo desse parâmetro (Tabela 1). 
Tabela 1 - Medida da Temperatura, por Ponto.

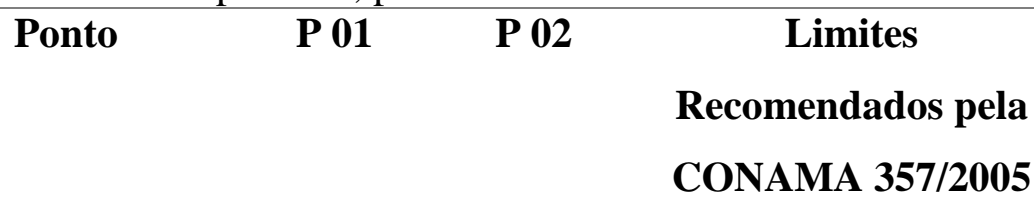

\begin{tabular}{lll}
\hline Valor & $27,36{ }^{\circ} \mathrm{C}$ & $27,1^{\circ} \mathrm{C}$ \\
encontrado &
\end{tabular}

Fonte: Autores, 2015.

\subsection{2 pH ( Potencial Hidrogeniônico )}

Cetesb (2009) afirma que o pH possui uma grande influência sobre os ecossistemas aquáticos, isso ocorre por causa da fisiologia de várias espécies. Em determinadas condições o $\mathrm{pH}$ pode contribuir para determinar o risco de elementos químicos tóxicos como metais pesados na água, outras condições podem desempenhar efeitos sobre as solubilidades de nutrientes.

De acordo com a Resolução CONAMA 357 o pH das águas doces classe 2 está enquadrada no valor de 6,0 a 9,0, portanto o $\mathrm{pH}$ dos pontos analisados está de acordo com o valor permitido (Tabela 2).

Tabela 2 - Medidas do $\mathrm{pH}$ dos pontos analisados.

\begin{tabular}{cccc}
\hline Ponto & P 01 & P02 & $\begin{array}{c}\text { Limites Recomendados } \\
\text { pela CONAMA 357/2005 }\end{array}$ \\
\hline $\begin{array}{c}\text { Valor } \\
\text { encontrado }\end{array}$ & 6,5 & 6,5 & 6,0 a 9,0
\end{tabular}

Fonte: Autores, 2015.

\subsubsection{Salinidade}

No ambiente estuarino, a temperatura e a salinidade podem variar horizontalmente e verticalmente na coluna d'água, sendo que esta diluição é o principal fator que controla a dispersão e atividade de animais e plantas, agindo como fatores limitantes à reprodução, ao crescimento e à distribuição de organismos (CONCEIÇÃO, 2013). 
Revista Ceuma Perspectivas, Edição Especial. I Fórum de Meio Ambiente do Estado do Maranhão, Ceuma.

Vol. 30, n०01, 2017.

ISSN Eletrônico: 2525-5576.

Conforme a Resolução CONAMA 357 de março de 2005, art. $2^{\circ}$ o corpo hídrico é classificado de águas doces quando sua salinidade é igual ou inferior a 0,5\%, os pontos analisados variam de $0,2 \%$ a $0,17 \%$ mostrando que esse parâmetro está de acordo com a Resolução confirmando que este corpo hídrico é de água doce.

\subsubsection{Sólidos Totais Dissolvidos (TDS)}

Os sólidos dissolvidos relacionados com a turbidez da água que afeta a redução de sua transparência, interferindo na penetração dos raios solares, ocasionando a diminuição da atividade fotossintética, é de extrema importância para os organismos fotossintetizantes interferindo inteiramente na produção de oxigênio dissolvido levando assim à sua redução, causando um grande impacto sobre o ecossistema aquático (ROCHA et al., 2010).

Os sólidos totais dissolvidos (TDS) variam de 186 a 210, comparados com a Resolução Conama 357 de março de 2005, esses valores estão de acordo com o permitido.

\subsubsection{Condutividade Elétrica}

A condutividade é a expressão numérica da capacidade de uma água conduzir a corrente elétrica. Depende das concentrações iônicas e da temperatura e indica a quantidade de sais existentes na coluna d'água e, portanto, representa uma medida indireta da concentração de poluentes (BRAGA et al,2005). Os valores da condutividade elétrica variam entre 365 a 421, sendo que na Resolução CONAMA de 357 de março de 2005, não consta o valor máximo para esse parâmetro.

\subsubsection{Oxigênio Dissolvido (OD)}

O oxigênio dissolvido é indispensável à sobrevivência dos organismos aeróbios. As concentrações de oxigênio dissolvido (OD) sofreram uma variação de $0,03 \mathrm{mg} / \mathrm{L}$ a 0,04 mg/L. De acordo com esse resultado, nota-se que os valores de OD não estão enquadrados na Resolução Conama 357 de março de 2005.

O oxigênio dissolvido é um dos principais parâmetros que caracterizam os efeitos da poluição das águas, decorrentes dos despejos orgânicos (MICHELINA et al., 
Revista Ceuma Perspectivas, Edição Especial. I Fórum de Meio Ambiente do Estado do Maranhão, Ceuma.

Vol. 30, $\mathrm{n}^{\circ} 01,2017$. ISSN Eletrônico: 2525-5576.

2006). Este é o caso da nascente do Rio Paciência, onde ocorre baixa oxigenação neste corpo hídrico, levando à proliferação de bactérias anaeróbias.

\subsection{Parâmetros Microbiológicos}

Coliformes totais e Escherichia coli

Após 24 horas as amostras da análise realizada foram retiradas da estufa, resultando em uma coloração amarelada em todos os frascos, indicação que naquela água possui coliformes totais (Figura 1 A). Após essa confirmação, utilizou-se a luz ultravioleta $6 \mathrm{~W}$, para constatar-se que naquelas amostras possui a presença da E. coli, sendo que amostra próxima à luz ultravioleta resulta em uma florescência de cor azul confirmando a presença da E. coli (Figura $1 \mathrm{~B}$ ). De acordo com as análises realizadas a água da nascente do Rio Paciência contem a presença de coliformes totais e Escherichia coli, um contaminante de origem fecal.

Figura $1 \mathrm{~A}$ - A presença de coliformes totais.

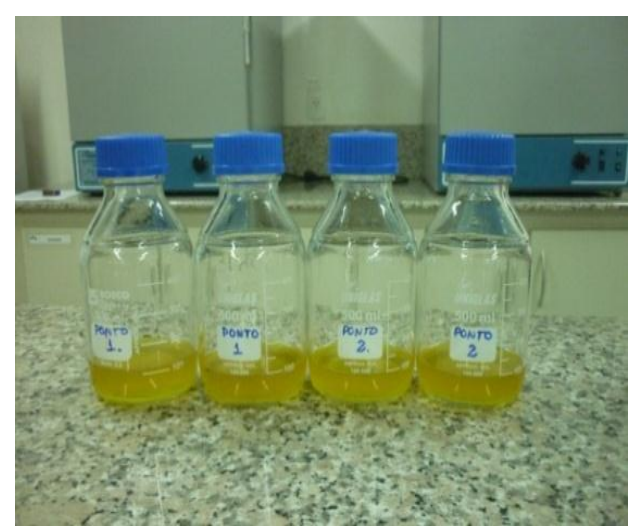

Fonte: Autores, 2015.
Figura 1 B - Presença da E. coli. na Luz

$$
\text { UV. }
$$
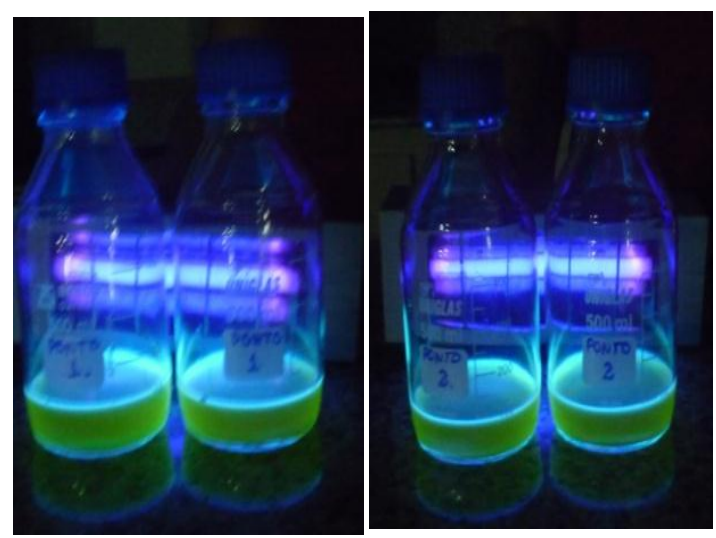
Revista Ceuma Perspectivas, Edição Especial. I Fórum de Meio Ambiente do Estado do Maranhão, Ceuma.

Vol. 30, $\mathrm{n}^{\circ} 01,2017$.

ISSN Eletrônico: 2525-5576.

\section{CONCLUSÕES}

Através das análises realizadas na nascente do Rio Paciência, aponta-se que os parâmetros físico-químicos analisados mostram que o $\mathrm{pH}$, a salinidade e os sólidos totais estão enquadrados na Resolução CONAMA 357, de 17 de março de 2005. Para águas doces de classe 2 , o oxigênio dissolvido é o único que não está de acordo com a Resolução, o valor permitido para esse parâmetro deve ser não inferior a $5 \mathrm{mg} / \mathrm{L} \mathrm{O}^{2}$, o valor analisado varia entre $0,03 \mathrm{mg} / \mathrm{L} \mathrm{O}^{2}$ a $0,04 \mathrm{mg} / \mathrm{L} \mathrm{O}^{2}$, este parâmetro constata que a água desta nascente está sendo poluída com despejo de efluentes. A temperatura e a condutividade elétrica não possuem na Resolução CONAMA 357/05 os valores máximos das águas doces de classe 2 para esses parâmetros.

Os parâmetros microbiológicos foram analisados por meio da técnica do Substrato Cromogênico Definido (Colilert), constatando a presença de coliformes totais e E. Coli, que são bactérias encontradas nas fezes humanas e de animais, encontradas em esgotos, águas naturais e solos que tenham recebido contaminação fecal recente, originária de efluentes domésticos.

A poluição deste corpo hídrico pode ser mitigada com uma ação do poder público minimizando os impactos causados pela descarga de efluentes neste corpo hídrico, visando também à educação ambiental das pessoas que moram no entorno daquela área, pois os mesmos possuem uma parcela de responsabilidade no impacto causado na nascente do Rio Paciência, pois este corpo hídrico está poluído por resíduos que possivelmente são descartados pelos próprios moradores daquela localidade, servindo de proliferação de vetores naquela área.

\section{REFERÊNCIAS}

BRAGA, Benedito et. al. Introdução à Engenharia Ambiental: o desafio do

desenvolvimento sustentável. $2^{\text {a }}$ Ed. São Paulo: Person Prentice Hall, 2005.

BRASIL. RESOLUÇÃO CONAMA N ${ }^{\circ} 001$ de 23.01.86. Estabelece as definições, as responsabilidades, os critérios básicos e as diretrizes gerais para uso e 
Revista Ceuma Perspectivas, Edição Especial. I Fórum de Meio Ambiente do Estado do Maranhão, Ceuma.

Vol. 30, $\mathrm{n}^{\circ} 01,2017$.

ISSN Eletrônico: 2525-5576.

implementação da Avaliação de Impacto Ambiental. Publicado no D.O. U de 17.02.86, p. 2548 e 2549.

BRASIL. RESOLUÇÃO CONAMA N ${ }^{\circ} 357$ de 17.03.05. Dispõe sobre a classificação dos corpos de água e diretrizes ambientais para o seu enquadramento, bem como estabelece as condições e padrões de lançamento de efluentes, e dá outras providências. Publicado no DOU no 53, de 18.03.2005, págs. 58-63.

\section{CETESB. Significado Ambiental e Sanitário das Variáveis de Qualidade das Águas} e dos Sedimentos e Metodologias Analíticas e de Amostragem. Série Relatórios. APÊNDICE A. São Paulo: Governo do Estado de São Paulo Secretaria do Meio Ambiente. 2009.

CONCEIÇÃO, Carlos Anderson Frazão. Avaliação físico-química e bacteriológica dos pontos de recarga de aquíferos na estação ecológica do sitio do rangedor em São Luís, Maranhão. 69f. Monografia (Graduação em Tecnólogo em Gestão Ambiental) - Faculdade Santa Terezinha, São Luís, 2013.

LYONS, B.p. et al. Microbial water quality and sedimentary faecal sterols as markers of sewage contamination in Kuwait. Marine Pollution Bulletin, v. 100, n. 2, p.689698, nov. 2015.

MACEDO, Lúcio Antônio Alves de. Qualidade Ambiental dos Rios da ilha de São Luís. Maranhão: Mestrado em Saúde e Ambiente, 2003. 74p.

MICHELINA, A. et al. Qualidade microbiológica de águas de sistemas de abastecimento público da região de Araçatuba, SP. Revista Higiene Alimentar, São Paulo, v. 20, n. 147, p. 90-95, 2006.

OCHOO, Benjamin; VALCOUR, James; SARKAR, Atanu. Association between perceptions of public drinking water quality and actual drinking water quality: A 
Revista Ceuma Perspectivas, Edição Especial. I Fórum de Meio Ambiente do Estado do Maranhão, Ceuma.

Vol. 30, nº1, 2017. ISSN Eletrônico: 2525-5576.

community-based exploratory study in Newfoundland (Canada). Environmental Research, v. 159, p.435-443, nov. 2017.

PONSADAILAKSHMI, S. et al. Evaluation of water quality suitability for drinking using drinking water quality index in Nagapattinam district, Tamil Nadu in Southern India. Groundwater For Sustainable Development, [s.1.], v. 6, p.43-49, mar. 2018.

QUEIROZ, A. M. Caracterização limnológica do lagamar do Cauípe - Planície Costeira do município de Caucaia - CE. 2003. 204 f. Dissertação (Mestrado em Desenvolvimento e Meio Ambiente) - Universidade Federal do Ceará - UFC, Fortaleza, CE, 2003.

RAMDANI, Amina et al. Physico-Chemical Water Quality in Some Regions of Southern Algeria and Pretreatment Prediction. Procedia Engineering, v. 33, p.335339, 2012.

RIOS, L.C.A. Avaliação do nível de contaminação do rio Itapecuru na zona urbana de Caxias-MA. Monografia (Graduação), CESC/UEMA. Caxias-MA, 2009.

ROCHA, Elisandro Santos. et al. Análise Microbiológica da Água de Cozinhas e/ou cantinas das Instituições de Ensino do Município de Teixeira de Freitas (Ba). Revista Baiana de Saúde Pública. v.34, n.3, p.694-705, 2010.

RODRIGUES, J. R. D. D.; JORGE, A. O. C.; UENO, M. Avaliação da qualidade das águas de duas áreas utilizadas para recreação do rio Piracuama-SP. Revista Biociências, v. 15, n.2, p. 88-94, 2009.

WU, Zhaoshi et al. Assessing river water quality using water quality index in Lake Taihu Basin, China. Science Of The Total Environment, v. 612, p.914-922, jan. 2018. 